\title{
KELAS AWET 25 JENIS KAYU ANDALAN SETEMPAT 'TERHADAP RAYAP KAYU KERING DAN RAYAP TANAH
}

\author{
(The Durability Class of 25 Local Reliable Wood Species \\ Against Termites)
}

\author{
Oleh/By \\ Ginuk Sumarni \& Mohammad Muslich ${ }^{1)}$ \\ 1. Pusat Litbang Hasil Hutan, Jl. Gunung Batu No. 5 Bogor, Tlp/Fax: 86333413-8633378
}

Diterima 8 Mei 2008; disetujui 11 Juni 2008

\begin{abstract}
Twenty five local reliable wood species were collected from forest areas in West Java for durability test. Wood samples measuring $5.0 \mathrm{~cm}$ length by $2.5 \mathrm{~cm}$ width by $2.0 \mathrm{~cm}$ thick were exposed to dry-wood termites (Cryptotermes cynocephalus Light.). Other samples measuring $2.0 \mathrm{~cm}$ length by $0.5 \mathrm{~cm}$ width by $0.5 \mathrm{~cm}$ thick. were tested against subterranean termites (Coptotermes curvignathus Holmgreen.). Results revealed that out of the 25 investigated wood species $9(36 \%)$ were classified as higbly durable wood (i.e. classes I and II) to Cryptotermes cynocephalus Light. and the rest i.e. 16 species (64\%) were classified at the lower durability performance (i.e. classes III, IV and V). The results also showed that only one out of 25 wood species (i.e. 4\%) was categorized resistant against Coptotermes curvignathus Holmgreen., and the remaining 24 wood species (96\%) were categorized in several durability classes (III, IV, and V).
\end{abstract}

Keywords: Durability class, Local reliable wood species, dry-wood termites, subterranean termites

\begin{abstract}
ABSTRAK
Dua puluh lima jenis kayu andalan setempat yang berasal dari beberapa daerah di Jawa Barat diuji keawetannya. Kayu contoh uji yang berukuran $5,0 \mathrm{~cm} \times 2,5 \mathrm{~cm} \times 2,0 \mathrm{~cm}$ diuji terhadap rayap kayu kering (Cryptotermes cynocephalus Light.). Kayu contoh uji $2,0 \mathrm{~cm}$ x 0,5 cm x 0,5 cm diuji terhadap rayap tanah (Coptotermes curvignathus Holmgreen.). Hasil penelitian menunjukkan bahwa 9 jenis (36\%) dari 25 jenis kayu yang diteliti masuk ke dalam kelas awet tinggi (kelas I dan II) terhadap Cryptotermes cynocephalus Light., dan sisanya yaitu 16 jenis (64\%) masuk ke dalam kelas awet rendah (kelas III, IV dan V). Hasil penelitian terhadap terhadap Coptotermes curvignathus Holmgreen. satu jenis (4\%) dari 25 jenis kayu yang diteliti masuk ke dalam kelas awet II, sisanya 24 jenis (94\%) masuk ke dalam kelas awet rendah (III, IV dan V).

Kata kunci: Kelas awet, jenis kayu andalan setempat, rayap kayu kering, rayap tanah
\end{abstract}




\section{PENDAHULUAN}

Jenis-jenis kayu yang berasal dari hutan alam yang biasa dipakai untuk keperluan bahan bangunan, mebel, barang kerajinan dan bahan industri perkayuan seperti meranti, merbau, keruing dan bangkirai dewasa ini makin terbatas pasokannya dan tidak seimbang dengan kebutuhan yang makin meningkat. Untuk memenuhi keperluan tersebut di atas, harus dicarikan penggantinya dengan jenis kayu lain yang berasal dari hutan alam dan atau yang ditanam masyarakat sebagai salah satu alternatif. Masyarakat dalam memilih kayu untuk keperluan tertentu biasanya hanya berdasarkan pengalaman atau kebiasaan yang diperoleh secara turun-temurun. Pemahaman mengenai sifat kayu dan kemungkinan pemanfaatannya belum banyak diketahui, termasuk terhadap jenis kayu andalan setempat yang banyak digunakan masyarakat.

Keawetan kayu adalah daya tahan alami suatu jenis kayu terhadap organisme perusak kayu, seperti jamur, serangga dan penggerek di laut serta di mana kayu tersebut dipergunakan. Keawetan suatu jenis kayu yang dipakai di bawah atap akan berbeda dengan yang digunakan di luar, keawetan kayu yang dipakai di darat akan berbeda dengan yang dipakai di laut. Demikian pula kayu yang dipakai di dataran rendah keawetannya berbeda dengan yang dipakai di dataran tinggi (Sumarni dan Roliadi, 2002).

Keawetan merupakan sifat kayu yang penting karena walaupun kelas kuatnya tinggi, tetapi manfaatnya akan banyak berkurang bila umur pakainya pendek. Umur pakai yang pendek sangat merugikan, karena biaya yang dikeluarkan tidak seimbang dengan umur pakainya. Sifat keawetan suatu jenis kayu dapat dipakai untuk bahan pertimbangan dalam mengambil keputusan apakah jenis kayu tersebut perlu diawetkan atau tidak apabila dipakai untuk keperluan tertentu. Pada tulisan ini disajikan hasil penelitian mengenai kelas awet 25 jenis kayu andalan setempat di daerah Jawa Barat terhadap rayap kayu kering (Cryptotermes cynocephalus Light.) dan rayap tanah (Coptotermes curvignathus Holmgreen.).

\section{BAHAN DAN METODE}

Penelitian ini menggunakan 25 jenis kayu andalan setempat yang berasal dari Jawa Barat yaitu marasi (Hymenea carboril L.), asem jawa (Tamarindus indica L.), balobo (Diplodiscus sp.), kundang (Ficus variegata BL.), ki kendal (Ehretia acuminata R.Br.), huru gading (Litsea odorifera Val.), ki sampang (Meliocope lunu-ankenda (Gaertn.) T.G. H.), sampora (Colona javanica B.L.), nyatoh (Pouteria duclitan Bachni.), ki hantap (Stercularia oblongata R.Br.), ki kuya (Ficus vasculosa Wall ex Miq.), ki lubang (Callophyllum grandiflorum JJS.), ki bancet (Turpinia sphaerocarpa Hassk.), ki bulu (Gironniera subasqualis Planch.), huru mentek (Lindera polyantha Boerl.), huru kacang (Neolitsea triplinervia Merr)., tunggeureuk (Castanopsis tunggurut A.DC.), ki endog (Acer niveum Bl.), beleketebe (Sloanea sigun Saysz), mimba (Azadiracbta indica Juss.), ki hiur (Castanopsis acuminatissima A.DC.), huru pedes (Cinnamomum iners Reinw. Ex Blume.), huru koja (Litsea angulata Bl.), ki kanteh (Ficus nervosa Heyne.), dan kelapa ciung (Horsfieldiaglabra Warb.).

Setiap jenis kayu dibuat contoh uji sebanyak 10 buah berukuran $5,0 \mathrm{~cm} \times 2,5 \mathrm{~cm} \times 2,0$ $\mathrm{cm}$ untuk rayap kayu kering (Cryptotermes cynocephalus Light.) dan 2,0 cm x 0,5 cm x 0,5 cm 
untuk rayap tanah (Coptotermes curvignathus Holmgreen.). Contoh uji diambil dari bagian batas teras dan gubal dipilih secara acak. Cara pengujian masing-masing sebagai berikut:

\section{A. Daya Tahan Terhadap Rayap Kayu Kering}

Pada salah satu sisi yang terlebar pada masing-masing contoh uji dipasang tabung gelas yang berdiameter $1,8 \mathrm{~cm}$ dengan ukuran tinggi $3,5 \mathrm{~cm}$. Ke dalam tabung gelas tersebut dimasukkan 50 ekor pekerja rayap kayu kering yang sehat dan aktif, kemudian contoh uji yang sudah berisi rayap disimpan di tempat yang gelap selama 12 minggu (Gambar 1). Pada akhir pengujian ditetapkan persentase rayap yang hidup, persentase pengurangan berat dan derajat serangan pada masing-masing contoh uji. Derajat serangan ditetapkan berdasarkan Martawijaya dan Sumarni (1978) sebagai berikut:

$$
\begin{aligned}
100 & =\text { utuh (tidak diserang) } \\
90 & =\text { sedikit } \\
70 & =\text { sedang } \\
40 & =\text { hebat } \\
0 & =\text { hebat sekali }
\end{aligned}
$$

dengan catatan bahwa bekas gigitan tipis pada permukaan kayu (surface nibbles) tidak dianggap sebagai serangan nyata. Guna menentukan klasifikasi kelas awet mengacu pada klasifikasi yang disusun oleh Sumarni et al. (2003).

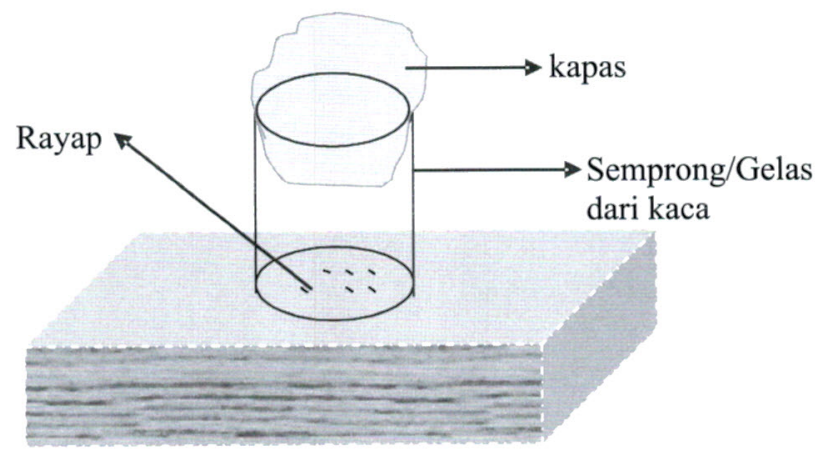

\section{Gambar 1. Pengujian contoh uji kayu terhadap rayap kayu kering Figure 1. Sample testing against dry-wood termites}

\section{B. Daya Tahan Terhadap Rayap Tanah}

Masing-masing contoh uji dimasukkan ke dalam jampot dengan cara berdiri pada dasar jampot dan disandarkan sedemikian rupa sehingga salah satu bidang terlebar contoh uji tersebut menyentuh dinding jampot. Ke dalam jampot tersebut dimasukkan pasir lembab sebanyak 200 gram yang mempunyai kadar air 7\% di bawah kapasitas menahan air (water bolding capacity). Selanjutnya ke dalam setiap jampot dimasukkan 200 ekor rayap yang sehat dan aktif terdiri dari $90 \%$ pekerja, kemudian jampot yang sudah berisi itu disimpan di tempat gelap selama 4 minggu (Gambar 2). Setiap minggu aktivitas rayap 
di dalam jampot diamati dan dicatat serta masing-masing jampot ditimbang. Jika kadar air pasir turun 2\% atau lebih, maka ke dalam jampot tersebut ditambahkan air secukupnya sehingga kadar air kembali seperti semula. Pada akhir pengujian ditetapkan persentase rayap yang hidup, persentase pengurangan berat dan derajat serangan pada masing-masing contoh uji. Derajat serangan ditetapkan berdasarkan Martawijaya dan Sumarni (1978) dengan penelitian seperti pada rayap kayu kering sebagai berikut:
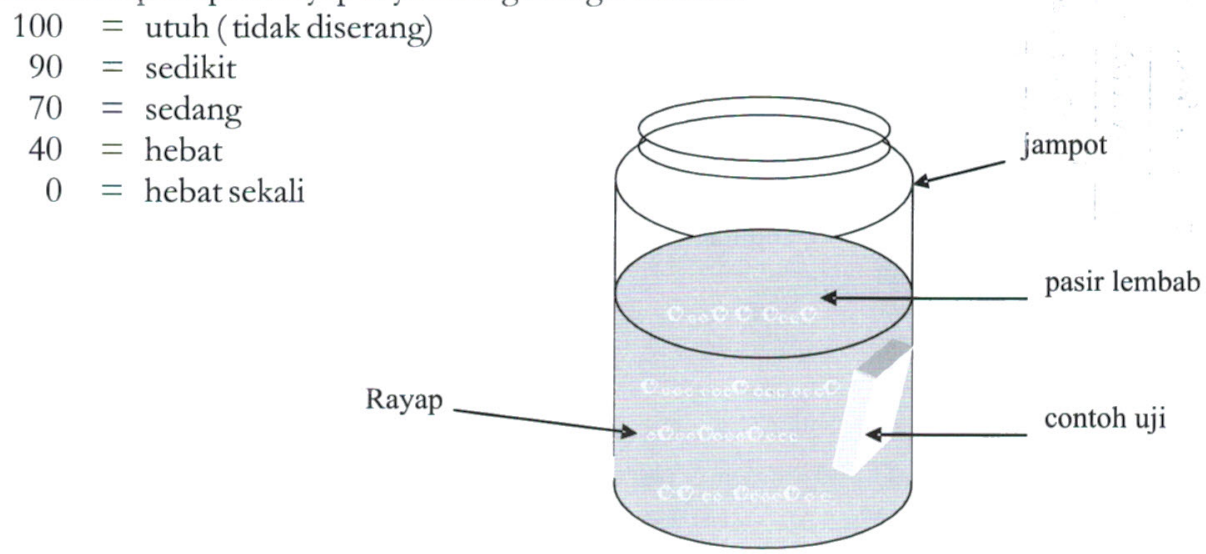

Gambar 2. Contoh uji kayu terhadap serangan rayap tanah Figure 2. Sample testing against subterranean termites

Dengan catatan bahwa bekas gigitan tipis pada permukaan kayu (surface nibbles) tidak dianggap sebagai serangan nyata. Guna menentukan klasifikasi kelas awet mengacu pada klasifikasi yang disusun oleh Sumarni dan Roliadi (2002).

\section{HASIL DAN PEMBAHASAN}

Hasil pengujian terhadap rayap kayu kering (Cryptotermes cynochephallus Light.) dan rayap tanah (Coptotermes curvignatbus Holmgreen.) dapat dilihat pada Tabel 1. Sebagai pembanding, dalam Tabel 1 dicantumkan pula kelas awet yang disusun menurut Oey Djoen Seng (1964). Sedangkan pengurangan berat, jumlah rayap (rayap kayu kering dan rayap tanah) yang hidup dan derajat serangan, sebagai dasar penetapan kelas awet dapat dilihat pada Lampiran 1. Pada Tabel 1 dapat dilihat bahwa dari 25 jenis kayu yang diuji mempunyai kelas awet yang berbeda. Kelas awet suatu jenis kayu terahadap rayap kayu kering belum tentu sama dengan kelas awet terhadap rayap tanah. Kelas awet tersebut di atas berbeda dengan kelas awet yang disusun oleh Oey Djoen Seng (1964), karena metode yang digunakan kemungkinan berbeda. Perbedaan hasil mungkin juga disebabkan oleh keadaan kayu dan faktor lingkungan pada saat pengujian. 


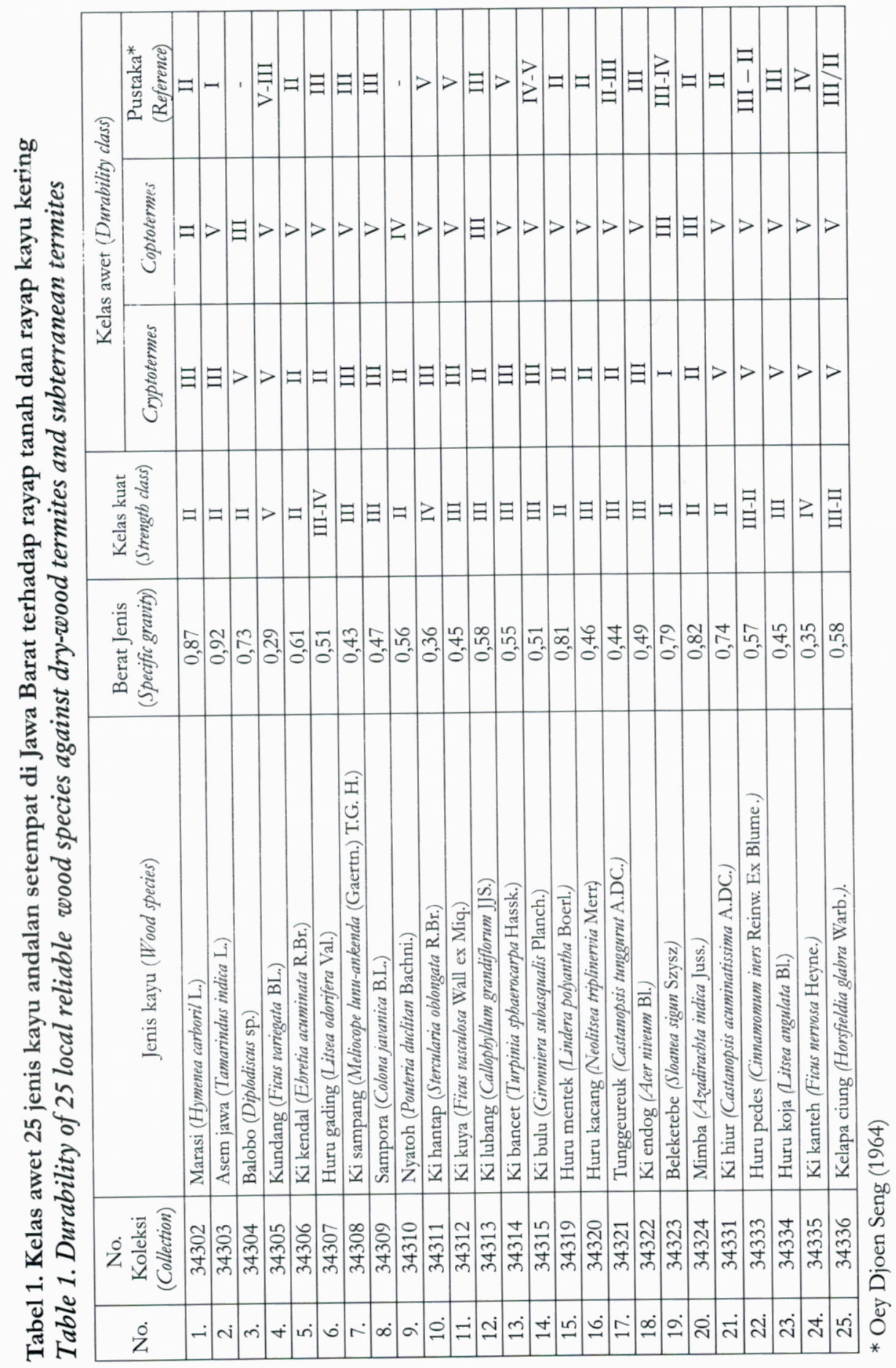


Dari 25 jenis kayu yang diteliti, hanya 1 jenis (4\%) yang masuk ke dalam kelas awet I terhadap rayap kayu kering, 8 (32\%) jenis masuk ke dalam kelas awet II dan sisanya (64\%) termasuk kelas awet III, IV dan V. Jenis kayu yang termasuk kelas 1 terhadap rayap kayu kering yaitu beleketebe (Sloanea sigun $S_{\text {zys }}$ ), sedangkan yang temasuk kelas II yaitu ki kendal (Ehretia acuminata R.Br.), huru gading (Litsea odorifera Val.), ki lubang (Callophyllum grandiflorum JJS.), huru mentek (Lindera polyantha Boerl.), huru kacang (Neolitsea triplinervia Merr.), tunggeureuk (Castanopsis tunggurut A.DC.) dan mimba (Azadirachta indica Juss.). Sementara kayu yang diuji terhadap rayap tanah, tidak ada yang termasuk kelas I dan hanya ada 1 jenis (4\%) saja yang termasuk kelas II, sisanya termasuk kelas III, IV dan V. Jenis kayu yang termasuk kelas awet II terhadap rayap tanah yaitu marasi (Hymenea carboril L.) dan sisanya termasuk kelas III, IV dan V. Jenis kayu yang termasuk kelas III, IV dan V terhadap rayap tanah berarti jenis kayu tersebut tidak awet bila digunakan di bawah atap yang berhubungan dengan tanah. Jenis kayu yang termasuk kelas awet III, IV dan V terhadap rayap kayu kering dan rayap tanah, dalam penggunaannya harus diawetkan agar umur pakai kayu dapat bertambah panjang.

Pada Tabel 1 juga membuktikan bahwa keawetan suatu jenis kayu bersifat relatif, yang dimaksud adalah suatu jenis kayu yang tahan terhadap organisme tertentu belum tentu tahan terhadap organisme yang lain. Beleketebe (Sloanea sigun $S_{\text {zysz) }}$ sangat tahan (kelas I) terhadap rayap kayu kering tapi tidak tahan terhadap rayap tanah (kelas III). Mimba (Azadirachta indica Juss.) dan ki lubang (Callophyllum grandiflorum JJS.) termasuk kelas awet II terhadap rayap kayu kering, akan tetapi termasuk kelas awet III terhadap rayap tanah. Huru mentek (Lindera polyantha Boerl.), buru kacang (Neolitsea triplinervia Merr.), tunggeureuk (Castanopsis tunggurut A.DC.), nyatoh (Pouteria duclitan Bachni.), buru gading (Litsea odorifera Val.) dan ki kendal (Ehretia acuminata R.Br.) termasuk kelas II terhadap rayap kayu kering, tetapi keenam jenis kayu tersebut sangat tidak tahan terhadap rayap tanah atau termasuk kelas awet V. Demikian sebaliknya marasi (Hymenea carboril L.) yang termasuk kelas awet II terhadap rayap tanah, ternyata termasuk kelas awet III terhadap rayap kayu kering. Balobo (Diplodiscus sp.) yang kurang tahan terhadap rayap tanah (kelas III), bahkan sangat tidak tahan terhadap rayap kayu kering (kelas V). Berdasarkan penilaian kelas awet terhadap kedua jenis rayap tersebut dan kelas awet yang disusun oleh Oey (1964), secara umum dari 25 jenis kayu yang diteliti yang paling awet terhadap organisme perusak adalah mimba (Azadirachta indica Juss.) dan Marasi (Hymenea carborilL.).

Dari hasil yang diperoleh pada penelitian ini, menunjukkan bahwa sebagian besar jenis kayu yang diteliti mempunyai kelas awet yang berbeda. Hal ini disebabkan karena setiap jenis kayu mempunyai kandungan zat ektraktif yang berbeda pula. Pada mimba (Azadirachta indica Juss.) secara umum mempunyai kelas awet yang paling baik dibandingkan dengan jenis kayu lainnya, hal ini mungkin disebabkan kayu tersebut mempunyai zat ektraktif yang bersifat racun. Ruskin (1993) menyatakan bahwa mimba mempunyai zat ektraktif berupa azadirachtin, salanin, mehantriol, nimbin dan nimbidin. Azadirachtin berperan sebagai ecdyson blocker atau zat yang dapat menghambat kerja hormon ecdyson dalam proses metamorphose pada rayap yang berakibat kematian (Chiu, 1988). Meskipun demikian, zat ekstraktif yang bersifat racun terhadap suatu organisme perusak, belum tentu bersifat racun terhadap organisme perusak lainnya. Sebagai contoh, tectochinon yang terdapat pada jati (Tectona grandis L.f.) bersifat repellent terhadap rayap kayu kering, namun tidak menunjukkan tanda-tanda beracun terhadap jamur perusak kayu (Caniophora cerebella Pers. dan Trametes lilacino-gilva Berk.), sedangkan pengaruhnya terhadap rayap tanah (Coptotermes lacteus Frogg. 
dan Nasutitermes exitiosus Hill.) adalah relatif kecil (Martawijaya, 1996). Kayu jeunging (Paraserianthes falcataria) mengandung saponin tahan terhadap jamur Poria vaporaria dan Coniophora cerebella, tetapi tidak tahan terhadap Schizophyllum communeae (Martawijaya, 1996). Dengan demikian nampak bahwa keawetan kayu tergantung kepada organisme yang menyerangnya.

Sementara bila diperhatikan pada Tabel 1, asem jawa (Tamarindus indica L.) mempunyai berat jenis paling tinggi $(0,92)$ di antara jenis lainnya, akan tetapi termasuk kelas awet III terhadap rayap kayu kering bahkan ternasuk kelas awet $\mathrm{V}$ terhadap rayap tanah. Demikian pula pada balobo (Diplodiscus sp.) yang mempunyai berat jenis $(0,73)$ termasuk agak tahan (kelas awet III) terhadap rayap tanah, tetapi sangat tidak tahan (kelas awet V) terhadap rayap kayu kering. Sebaliknya pada ki lubang (Callophyllum grandiflorum JJS.) yang mempunyai berat jenis 0,58 relatif lebih rendah dari kedua jenis kayu tersebut, ternyata termasuk tahan (kelas II) terhadap rayap kayu kering dan agak tahan (kelas awet III) terhadap rayap tanah. Pada umumnya tidak ada sanggahan terhadap adanya pengaruh berat jenis terhadap keawetan kayu, kayu yang mempunyai berat jenis tinggi keawetannya akan makin baik. Tetapi hubungan ini hanya dianggap berlaku untuk kayu yang berasal dari satu genus saja (Oey, 1964; Muslich dan Sumarni, 2006). Dalam penelitian Oey (1964) mengenai berat jenis kayu Indonesia yang meliputi ratusan jenis, ternyata bahwa hubungan antara berat jenis dengan keawetan kurang berlaku umum dan kurang nyata, tidak seperti hubungan antara berat jenis dengan kekuatan kayu. Xantopbyllum stipitatum yang mempunyai berat jenis 1,04, Planchonella obovata 1,01, Tamarindus indicus 0,84 tidak tahan terhadap serangan jamur dan serangga dibandingkan dengan Tectona grandis yang mempunyai berat jenis 0,67 (Oey, 1964). Jika kita membandingkan berbagai jenis kayu yang mempunyai berat jenis tinggi mempunyai keawetan yang berada di bawah jenis kayu yang berat jenisnya lebih rendah, dalam hal ini diduga bahwa zat ekstraktif yang memegang peranan lebih penting dari pada berat jenis.

Sehubungan dengan hasil penelitian di atas, mengenai kelas awet kayu terhadap rayap kayu kering, berbeda dengan kelas awet kayu terhadap rayap tanah dan juga berbeda dengan kelas awet yang disusun oleh Oey Djoen Seng (1964). Klasifikasi keawetan yang disajikan dalam tulisan ini didasarkan atas hasil pengujian pada kondisi laboratorium. Sedangkan klasifikasi kelas awet kayu menurut Oey Djoen Seng (1964) dicatat menggunakan data yang tercantum pada etiket herbarium yang pada waktu pengumpulan jenis kayu tersebut. Catatan dibuat berdasarkan keterangan penduduk sekitar hutan tempat jenis pohon tersebut tumbuh yang kemudian dicocokkan dengan data dari berbagai sumber. Dengan demikian, kelas awet yang ditetapkan oleh Oey Djoen Seng (1964) belum didasarkan kepada hasil pengujian di laboratorium. Oleh karena itu terdapat perbedaan dalam hasil klasifikasi di antara kedua metode. Dengan demikian nampak klasifikasi keawetan kayu selain tergantung pada organisme yang menyerang, juga kemungkinan tergantung kepada metode pengujian yang dipakai.

\section{KESIMPULAN}

Pengujian kelas awet dari 25 jenis kayu andalan setempat di daerah Jawa Barat terhadap rayap kayu kering (Cryptotermes cynocephalus Light.) dan rayap tanah (Coptotermes curvignathus Holmgreen.) dapat disimpulkan sebagai berikut: 
1. Kayu yang mempunyai kelas awet tinggi terhadap rayap kayu kering belum tentu mempunyai kelas awet yang sama terhadap rayap tanah. Demikian juga kayu yang mempunyai kelas awet tinggi terhadap rayap tanah belum tentu mempunyai kelas awet yang sama terhadap rayap kayu kering.

2. Mimba (Azadirachta indica Juss.) dan marasi (Hymenea carboril L.) secara umum mempunyai kelas awet yang paling baik dibandingkan dengan jenis kayu yang diteliti lainnya.

\section{DAFTAR PUSTAKA}

Chiu, S.F. 1988. Recent advances in research on botanical insecticides in China. South China Agricultural University, Guangzhou. pp. 69-77.

Martawijaya, A. 1996. Keawetan kayu dan factor yang mempengaruhinya. Petunjuk Teknis. Pusat Litbang Hasil Hutan, Bogor.

Martawijaya, A dan G. Sumarni. 1978. Daya tahan sejumlah jenis kayu Indonesia terhadap Cryptotermes cynocephalus Light. Laporan No. 129. LPHH, Departemen Pertanian, Bogor.

Muslich, M dan G. Sumarni. 2006. Keawetan 25 jenis kayu Dipterocarpaceae terhadap penggerek di laut. Jurnal Penelitian Hasil Hutan. 24(3): 191-200. Pusat Litbang Hasil Hutan, Bogor.

Oey Djoen Seng. 1964. Berat jenis dari jenis-jenis kayu Indonesia dan pengertian beratnya kayu untuk keperluan praktek. Pengumuman No. 1. Lembaga Penelitian Hasil Hutan, Bogor.

Ruskin, F.R. 1993. Neem: a tree for solving global problems. National Academy Press, Washington. D.C.

Sumarni, G. dan H. Roliadi. 2002. Daya tahan 109 jenis kayu Indonesia terhadap rayap tanah (Coptotermes curvignathus Holmgreen). Buletin Penelitian Hasil Hutan 20(3): 177185. Pusat Penelitian dan Pengembangan Teknologi Hasil Hutan., Bogor.

Sumarni, G. H. Roliadi dan A. Ismanto, 2003. Keawetan 99 Jenis Kayu Indonesia Terhadap Rayap Kayu Kering. Buletin Penelitian Hasil Hutan Vol.21 No.3. Pusat Penelitian dan Pengembangan Teknologi Hasil Hutan, Bogor. 
Kelas Awet 25 Jenis Kayu Andalan Setempat Terhadap .... (Ginuk Sumarni \& Mohammad Muslichi)

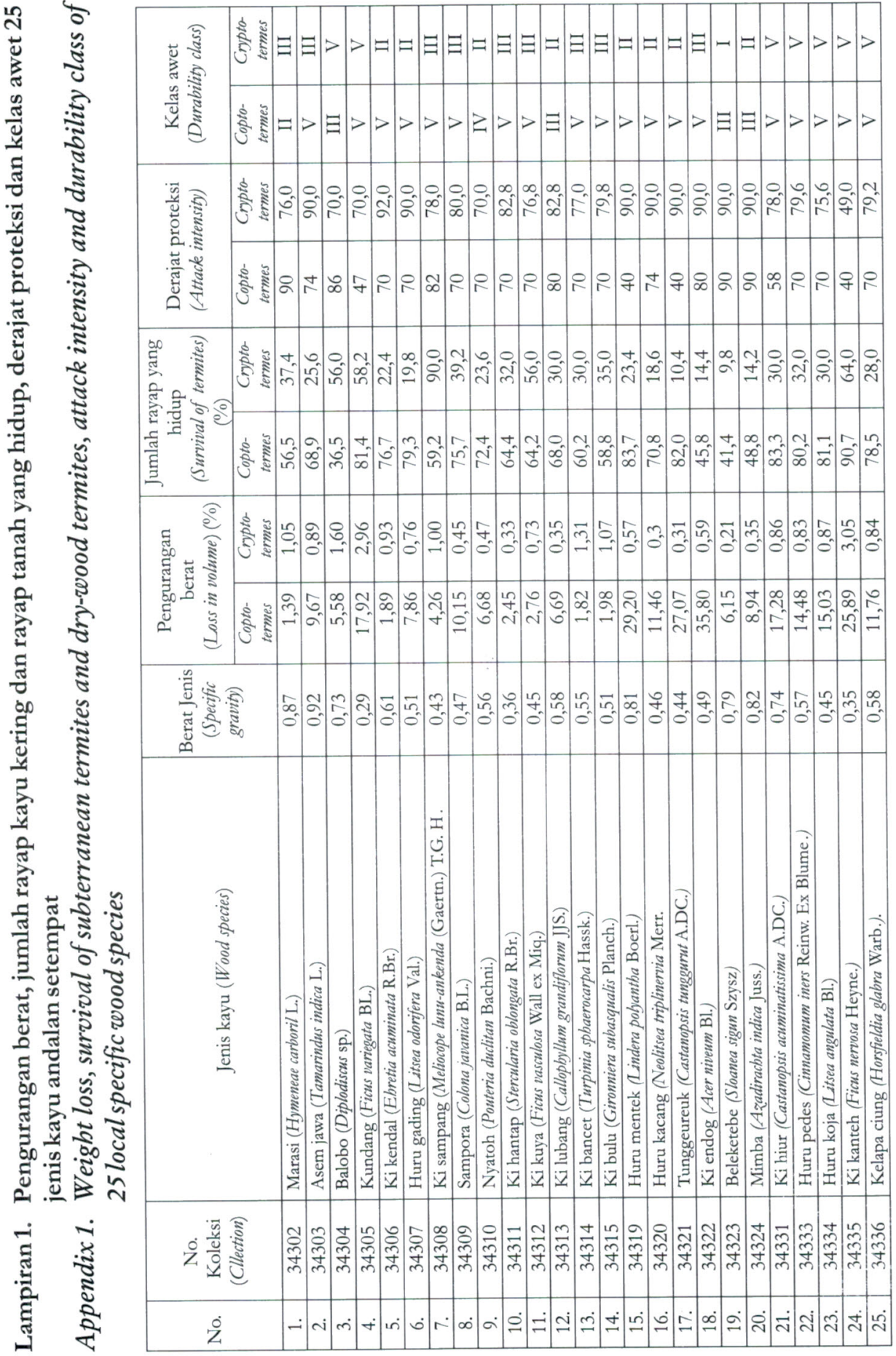

